\title{
Understanding the Role of Core Developers in Open Source Software Development
}

\author{
Ju Long \\ Texas State University- San Marcos, San Marcos, TX, USA \\ julong@txstate.edu
}

\begin{abstract}
Most Open Source Software projects fail, while only very few succeed. In this study, we examine the factors that may influence the success or failure of OSS projects. We particularly focus on OSS core developer roles. We separate core developers from other developers in the community and empirically examine their different roles. Based on our analysis of a data set comprising 300 open source projects, we demonstrate that both core-developer leadership and project-advocating activities are crucial in the development of OSS projects. This research also offers insight into the sustainability of OSS development and provides advice to practitioners in the OSS community on how to make their projects successful.
\end{abstract}

Keywords: Software Development, Open Source Software, Sustainability, Software Developers, Development Model

\section{Introduction}

The model of open source software (OSS) represents a disruptive paradigm in the software industry. Compared with the traditional proprietary software development, OSS is a radically new paradigm (Moody, 2001; Raymond, 2005; Sharma, Sugumaran, \& Rajagopalan, 2002). With OSS, software source code is freely available for anyone to view, download, modify and redistribute as long as it is under the same open source license (see http://www.opensource.org ). Most open source software projects rely entirely on the voluntary efforts of a community of developers (although some projects are coordinated and led by commercial entities). Such a voluntary community process keeps the cost of development and testing low. The nearly zero total cost of ownership (TCO) gives open source software a strong competitive edge.

A few projects initiated by the OSS community, such as GNU, Linux, Apache, MySQL and PHP, have achieved extraordinary success. However, except for these few successful projects, the majority of the open source projects have had lackluster performance, with little development momentum behind them (Thomas \& Hunt, 2004).

Material published as part of this journal, either on-line or in print, is copyrighted by the Informing Science Institute. Permission to make digital or paper copy of part or all of these works for personal or classroom use is granted without fee provided that the copies are not made or distributed for profit or commercial advantage AND that copies 1) bear this notice in full and 2) give the full citation on the first page. It is permissible to abstract these works so long as credit is given. To copy in all other cases or to republish or to post on a server or to redistribute to lists requires specific permission and payment of a fee. Contact Publisher@InformingScience.org to request redistribution permission.
Why do some open source software projects achieve success while others do not? What are the factors that influence the success or failure of open source software projects? Several researchers have tried to address these questions and have generated very insightful results (e.g. Crowston, Annabi, Howison, \& Masango, 2004; Hann, Slaughter, Roberts, \& Fielding, 2002; Stewart, Ammeter, \& Maruping, 2005). Our research 
contributes to this prior literature in several important aspects. First, we have separated the OSS development workforce into two distinct groups - core developers and non-core developers - and studied their roles in the OSS development process. Prior research on OSS development has rarely distinguished between core and non-core developers, nor systematically examined the impact of core developers on the fate of an OSS project. Second, our research is based on a dataset of 300 open source projects. These projects not only include successful projects but also less successful ones. By examining projects from both realms, we can potentially gain a better understanding of the entire OSS ecosystem.

Our research addresses three important pillars of information systems research: information, information technology, and organizations. The open source model is a radically new model to gather information, create new information technology products, and to generate new knowledge. In the open source model, information flows in a loosely connected social network that is formed by thousands of developers. New knowledge is generated through volunteer work from these developers. The organizational structure is drastically different from the structure in traditional software development organizations. By analyzing the organizational structure of OSS projects, we have demonstrated several important factors that are related to OSS project success. Our research could shed some light on the sustainability of OSS as a new model of knowledge creation.

The remainder of this paper is organized as follows. First, we develop research hypotheses based on previous theories on OSS development and theories from organizational science. Next, we discuss the study's methodology and present results of the study. Last, we conclude the paper and examine future research topics.

\section{Theoretical Framework and Hypotheses}

Compared with the proprietary software development, open source developers have distinctive organizational structure, development process, and culture (Sharma et al., 2002). In proprietary software development process, there is only one development entity, being the software developers who are paid to work for the company. In the open source development process, however, there are two development entities: a small number of core developers (usually less than 15 people), and a large number of anonymous developers from the community (Mockus, Fielding, \& Herbsleb, 2000, Schmidt \& Porter, 2001). To study why an OSS project succeeds or fails, it is important to examine the roles of these two developer groups separately.

To distinguish between the roles of core developers and community developers, we need to have a clear understanding of the organizational structure of OSS projects. Although OSS projects are radically different from proprietary software projects, their organizational structure could still be analyzed following the common organizational dimensions (Sharma et al., 2002). Therefore, we employ an established theoretical framework based on the organization theory literature and develop our research hypotheses accordingly (Miles \& Snow, 1978; Robey, 1991; Sharma et al., 2002). Based on this framework, we analyze different roles of core developers and community developers along the following dimensions: division of labor, co-ordination mechanisms, distribution of decision-making authority, organizational boundary, and development process. These

dimensions have been widely used to analyze traditional organizational structures in existing literature (March \& Simon, 1958; Mintzberg, 1972; Nohria, 1995; Sharma et al., 2002). Figure 1 shows the framework of the organizational structure, which we have used. 


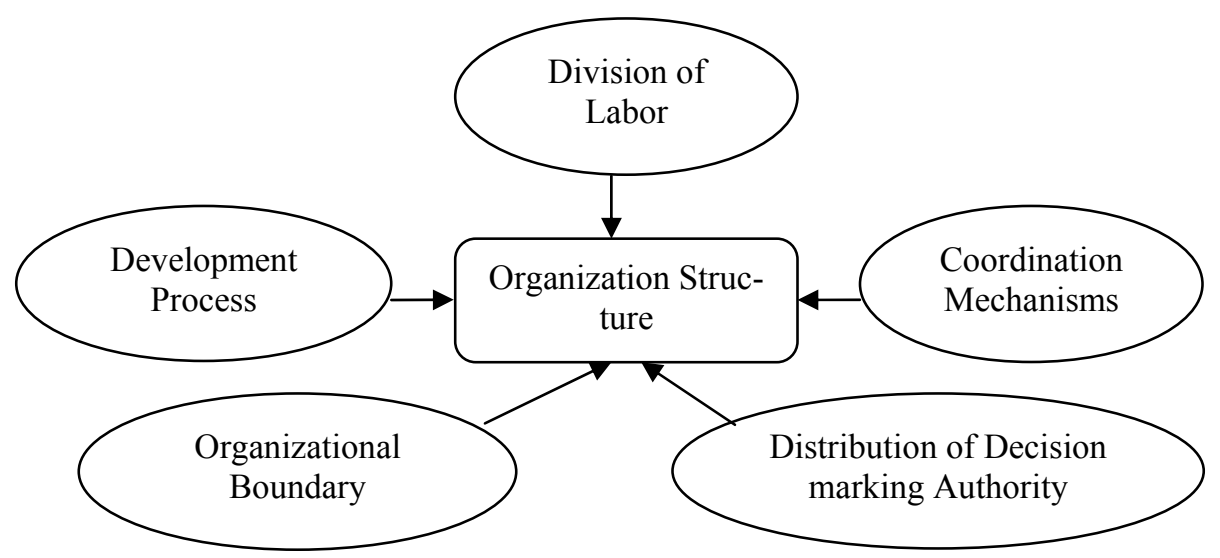

Figure 1: Dimensions of Organizational Structure

\section{Organizational Structure of Community Developers}

\section{Coordination mechanisms and distribution of decision making authority}

In traditional organizations, coordination mechanisms are often based on hierarchical supervision, plans and procedures (Miles \& Snow, 1978; Robey, 1991). The distribution of decision-making authority is highly centralized, while the strategy and execution are often separated (Sharma et al., 2002). In the OSS development process, however, there is no single central decision maker. Developers in the community make judgments on what tasks to do and how to do them (Fielding, 1999; Markus, Manville, \& Agres, 2000; Mockus et al., 2000). The coordination mechanisms are highly de-centralized and democratic (Raymond, 2005). Developers in the community use online forums as the essential channel to coordinate development activities. Many development tasks are assigned, and many development decisions are made through a forum (Sharma et al., 2002). Maintaining an active online forum is crucial to keep the communication channel open for developers. Thus, the number of messages posted in the forum could indicate how active the developers from the community are. The more active the developers, the more successful the project could be. Hence, our first hypothesis is:

H1a: The number of messages in the forum could be positively correlated with the OSS project success.

\section{Division of labor and development process}

In traditional organizations, division of labor is often decided by inputs and outputs analyses (Nohria 1995; Sharma et al., 2002). However, division of labor in OSS projects is drastically different in that a large number of anonymous developers volunteer to develop the project. These developers are organized in a loosely centralized and networked community - a "Bazaar" (Raymond, 2005; Tirole \& Lerner, 2002). There is no formal development plan or strict schedule to follow (Mockus et al. 2000; Schmidt \& Porter, 2001). The developers choose in which projects to participate and how much effort to put forth according to their own schedule. This open organizational structure encourages new contributors to join. By remaining open to new contributors, the project could have an unlimited supply of innovative ideas (Fielding, 1999; Raymond, 2005).

Reporting bugs and patches are two main ways developers contribute to the OSS development process. A large number of bug reports and patch reports generally show that the project attracts a lot of attention from the developer community. Therefore, we propose the following hypotheses: 
H1b: The number of bug reports from non-core developers could be positively related to OSS project success.

H1c: The number of patch reports from non-core developers could be positively related to OSS project success.

\section{Organizational Structure of Core Developers}

\section{Division of labor}

Because of the important role of non-core developers in the OSS development, attracting talented developers and keeping them motivated are crucial in the project development process. This is especially important during the early development stage so that the number of developers could reach a critical mass. Core developers are responsible for attracting and motivating developers in the community.

One important way to do so is to update the project and release new versions of the project frequently. Frequent updates indicate that core developers make efforts to promote the project and motivate developers in the community. Frequently updated projects often attract more developers to participate because their contributions could be valued (Krishnamurthy, 2002). New versions of the project also provide the developers with new tasks. Another way to attract and motivate developers is to broadcast news about the project in the community. Thus, we propose the following hypotheses:

H2a: The number of file project releases could be positively related to OSS project success.

H2b: The number of news releases could be positively related to OSS project success.

\section{Coordination mechanisms}

To communicate with each other, developers use e-mail lists as an essential channel to coordinate development activities. E-mail is an indicator of the activity level of core developers. Another important channel to coordinate the development activities is the concurrent version system (CVS) (Crowston et al. 2004; Sharma et al. 2002). The total number of CVS updates could indicate how active the core developers are. Thus,

H3a: The number of email lists could be positively related to OSS project success.

H3b: The number of CVS could be positively related to OSS project success.

\section{Distribution of decision making authority}

An important characteristic of OSS project structure is self-governance (Markus et al., 2000; Raymond, 2005). Compared to OSS projects, most corporate projects have a much stronger belief in central planning. However, OSS projects are different. The OSS project almost always starts with a single developer. If after the first couple of releases the project often starts to grow, other developers would volunteer to join in (Thomas \& Hunt, 2004). However, that does not mean that there is no centralized decision making. The core developers set the goal and the mission of the project (Thomas \& Hunt, 2004). The right mission attracts more developers to join. Core developers are also responsible for dividing the projects into different tasks to be handled by individuals or teams (Sharma et al., 2002). Coordination among these tasks is also the responsibility of core developers. All these activities cannot be handled by one or two core developers. More core developers could mean more talents and resources to fulfill these responsibilities. Therefore, we posit that:

H4: The number of active core developers could be positively related to OSS project success. 


\section{Methodology}

Empirical data are collected from the SourceForge.Net website. SourceForge.net provides a centralized place for open source developers to develop their projects. It is the world's largest OSS projects repository. It had 89,103 open source projects and 935,651 registered developers, when we collected the data. It thus provides some of the best empirical data on OSS research. Our data sample consists of 300 OSS projects t. They are randomly selected from both the more popular projects and the less popular ones. SourceForge.NET provides detailed data on project activities across the entire life span of the project.

To measure the project success, we examined the previous literature. A literature review has demonstrated that there is a wide range of measures of project success. The field has not settled on any one measure, or a matrix of measures (Crowston, Annabi, Howison, \& Masango, 2005). Some of the possible measures include: lines of code per programmer per year (Mockus et al., 2000), speed in closing bugs or trackers items (Stewart \& Gosian, 2006), or modularity of source code (Shaikh and Cornford, 2003).

Among the range of measures of project success, a highly popular one is the number of downloads of the software (Crowston et al., 2005). How many times the software has been downloaded is a good indicator of the use of the software. It is noteworthy that when users and developers download the software, the source code is downloaded together with the software since the source code is freely available. If the project could attract many developers and users to download it, it could indicate that the project is popular and successful (Crowston et al., 2004). The number of downloads has been used in several studies to measure the project success (Crowston et al., 2004; Krishnamurthy, 2002; Raja \& Tretter, 2006; Stewart \& Gosain, 2006).

Independent variables are: the number of developers, the number of messages in the forums, the number of mailing lists, the number of bug reports, the number of patch reports, the number of CVS reports, the number of file releases, and the number of news releases.

To check data quality and validate assumptions for the statistical procedure, we used the frequency procedure to obtain the summary of each individual variable. As shown in Table 1, the distribution of variable values is asymmetric and skewed. This is because the data set includes some of the most popular projects, whose data are skewed toward the left.

Table 1. Frequency Table before Data Transformation

\begin{tabular}{|l|l|l|l|l|l|l|l|}
\hline & Forum & \multicolumn{1}{|c|}{ Bug } & Patch & \multicolumn{1}{|c|}{ CVS } & Release & News & Download \\
\hline N Valid & 151 & 299 & 299 & 293 & 273 & 220 & 291 \\
N Missing & 149 & 1 & 1 & 7 & 27 & 80 & 9 \\
Mean & 577.54 & 212.97 & 34.02 & 4071.81 & 18.34 & 10.39 & 355017.53 \\
Median & 114 & 49 & 3 & 1413 & 12 & 6 & 24545 \\
S.D. & 1378.12 & 650.62 & 189.38 & 11014.05 & 21.03 & 14.77 & 1839506.96 \\
Skew & 4.39 & 7.34 & 12.12 & 8.32 & 2.55 & 4.24 & 10.16 \\
\hline
\end{tabular}

The large positive skew could inflate the standard deviation to a point where it is no longer useful as a measure of the spread of data values. In order to increase the reliability of the data analysis, we conducted a $\log$ transformation, so that the distribution of the variable values is brought closer to normal. Table 2 shows the frequency table of the variables after the $\log$ transformation. We can see that the transformation has brought the distribution closer to normal. 
We also used factor analysis to perform data reduction. In our hypotheses development, we propose the performance of the projects is correlated with a set of predictors. However, many of these variables are correlated among themselves. We use factor analysis to remove redundant and highly correlated variables from the data file, and replace the data file with a smaller number of uncorrelated variables. Factor analysis has also allowed for examining latent variables that are underlying the relationships between the manifest variables.

Table 2. Frequency Table after Data Transformation

\begin{tabular}{|l|l|l|l|l|l|l|l|}
\hline & Forum & Bug & Patch & CVS & Release & News & Download \\
\hline N Valid & 151 & 290 & 197 & 288 & 272 & 218 & 287 \\
N Missing & 149 & 10 & 103 & 12 & 28 & 82 & 13 \\
Mean & 4.79 & 4 & 2.28 & 7.2 & 2.37 & 1.82 & 10.32 \\
Median & 4.74 & 4 & 2.2 & 7.29 & 2.48 & 1.79 & 10.16 \\
S.D. & 1.81 & 1.63 & 1.63 & 1.54 & 1.1 & 1 & 2.12 \\
Skew & 0.21 & 0.92 & 0.51 & -0.27 & -0.26 & 0.22 & 0.23 \\
\hline
\end{tabular}

The variables included in the factor analysis are: the number of developers, the number of messages posted on the forum (log transformed), the number of bug reports (log transformed), the number of patch reports (log transformed), the number of CVS (log transformed), the number of file releases (log transformed), the number of news releases (log transformed), and the number of mailing lists. We deployed orthogonal factor rotation to retrieve the components. Component score variables were, then, used in place of the 8 original variables to avoid the linearity in the regression analysis. We checked the plots of the component scores for outliers and non-linear associations between the components and did not find abnormalities in the component scores.

Finally, we used linear regression to model the value of the dependent variable - success of the projects - with its linear relationship to one or more predictors. We have assumed that there is a linear relationship between the dependent variable and each predictor.

\section{Results}

Based on the extraction communalities table from the factor analysis (Table 3), we extracted three components with the eigen-value greater than one. These components explain about $67 \%$ of the variability in the original eight variables.

The first component is correlated with the number of forums, the number of patch reports, and the number of bug reports. This finding is consistent with the literature on OSS coordination mechanisms and development process. Because many development tasks are assigned to non-core developers through the forums (Sharma et al., 2002), and non-core developers contribute to the project development by submitting bug reports and patch reports (Raymond, 2005; Sharma et al., 2002), we could use the first component to indicate activities of the non-core developers.

The second component is associated with the number of developers, the number of CVS updates, and the number of mailing lists. This also is in accord with the literature: CVS systems and email lists are two important channels for the core developers to coordinate the development activities (Sharma et al., 2002; Thomas \& Hunt, 2004). Therefore, we could use this component as the indicator of core developers' activities. 
Table 3. Extraction Communality Table

\begin{tabular}{|l|l|l|l|}
\hline Component & $\begin{array}{c}\text { Eigen- } \\
\text { Value }\end{array}$ & $\begin{array}{c}\text { \%o of Vari- } \\
\text { ance }\end{array}$ & $\begin{array}{c}\text { Cumulative } \\
\%\end{array}$ \\
\hline $\mathbf{1}$ & 3.846 & 38.460 & 38.460 \\
$\mathbf{3}$ & 1.765 & 17.652 & 56.112 \\
$\mathbf{4}$ & 1.143 & 11.426 & 67.538 \\
$\mathbf{5}$ & .947 & 9.468 & 77.006 \\
$\mathbf{6}$ & .886 & 8.863 & 85.869 \\
$\mathbf{7}$ & .745 & 7.452 & 93.321 \\
$\mathbf{8}$ & .396 & 3.960 & 97.281 \\
\hline
\end{tabular}

The third component is correlated with the number of file releases and the number of news releases. As we have proposed before, updating new files and news about the projects are two main responsibilities of core developers. These two variables could indicate core developers' activities in promoting and publicizing the project.

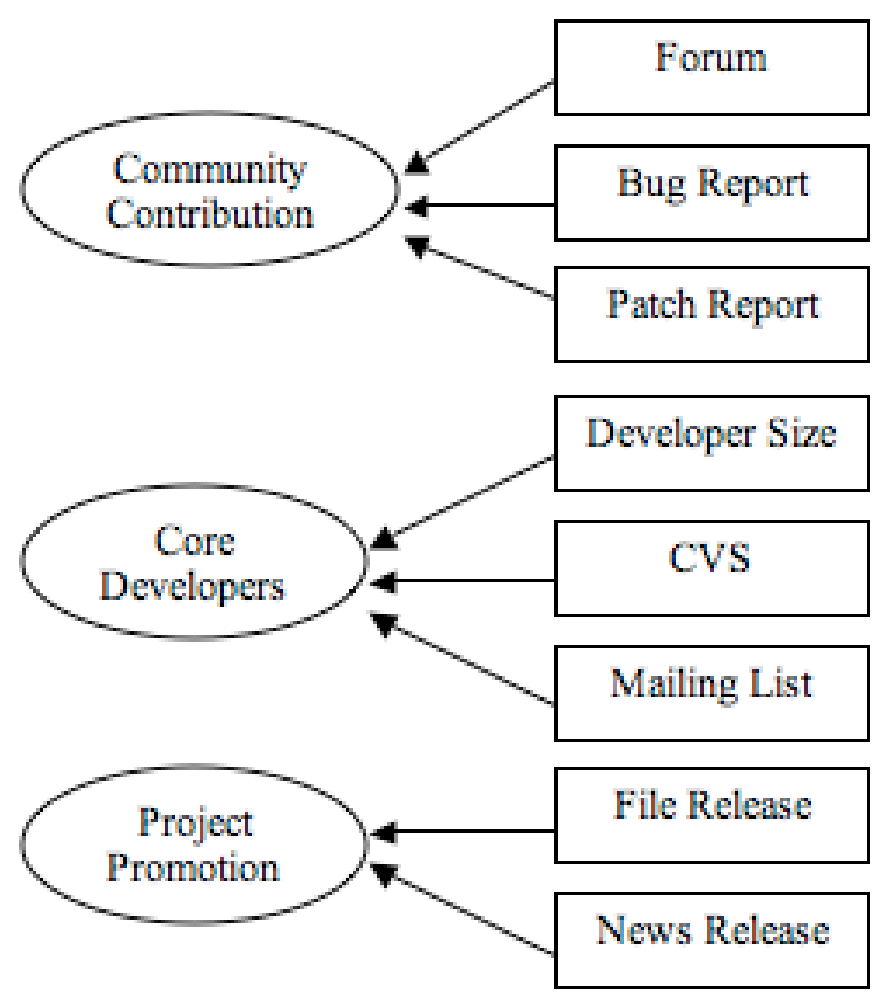

Figure 2. Principal Components

This result is consistent with previous literature that core developers are responsible for promoting and advocating the project in the developer community (Krishnamurthy, 2002; Sharma et al., 2002). The relationship between these extracted components and their variables are demonstrated 
in Figure 2. Note that the square contains the manifest variables, while the latent variables (extracted components) are in the circle.

As we specified before, we use the number of downloads as the indicator of project success. Thus, log-transformed number of downloads is the dependent variable in the model. The independent variables, i.e. the predictors, are the factors we extracted in the factor analysis. We use the component score of each factor in the model.

The ANOVA resulted in a significant $\mathrm{F}$ statistic, indicating a strong prediction power of the factors (Tables 4 and 5). The regression model proved to be effective in modeling success of the project, as it explains nearly a half of the variation ( $\mathrm{R}$ Square $=.465)$.

Table 4. ANOVA Results

\begin{tabular}{|l|l|l|l|l|}
\hline Mode 1 & R & R Square & Adjusted R Square & Std. Error of the Estimate \\
\hline $\mathbf{1}$ & $.682(\mathrm{a})$ & .465 & .423 & 1.53624 \\
\hline
\end{tabular}

Table 5. ANOVA Results

\begin{tabular}{|l|l|l|l|l|l|l|}
\hline Mode 1 & & \multicolumn{1}{|c|}{$\begin{array}{c}\text { Sum of } \\
\text { Squares }\end{array}$} & \multicolumn{1}{|c|}{ d.f. } & \multicolumn{1}{|c|}{$\begin{array}{c}\text { Mean } \\
\text { Square }\end{array}$} & F & Sig. \\
\hline $\mathbf{1}$ & Regression & 131.077 & 5 & 26.215 & 11.108 & $.000(\mathrm{a})$ \\
& Residual & 151.042 & 64 & 2.360 & & \\
& Total & 282.119 & 69 & & & \\
\hline
\end{tabular}

Judging from the coefficient table (Table 6), we can determine whether the predictors are significant.

Table 6. Coefficient of ANOVA

\begin{tabular}{|c|c|c|c|c|c|c|}
\hline Model & & $\begin{array}{c}\text { Unstandardized } \\
\text { Coefficients }\end{array}$ & \multicolumn{2}{|c|}{$\begin{array}{l}\text { Standardized } \\
\text { Coefficients }\end{array}$} & $\mathbf{T}$ & Sig. \\
\hline \multirow[t]{5}{*}{1} & & B & Std. Error & Beta & & \\
\hline & (Constant) & 11.071 & .184 & & 60.295 & .000 \\
\hline & $\begin{array}{l}\text { Community } \\
\text { Contribution }\end{array}$ & .828 & .185 & .410 & 4.480 & .000 \\
\hline & Core Developers & .745 & .185 & .368 & 4.027 & .000 \\
\hline & Project Promotion & .620 & .185 & .306 & 3.350 & .001 \\
\hline
\end{tabular}

As we have hypothesized, the contributions from the non-core developers in the community, efforts from core developers, and project promotion all play significant roles in OSS project success. By applying the multi-collinearity test, we determined that there was no significant multicollinearity. 


\section{Discussion}

Our analysis confirms our hypotheses $\mathrm{H} 1 \mathrm{a}, \mathrm{H} 1 \mathrm{~b}$, and $\mathrm{H} 1 \mathrm{c}$ that the number of messages in the forum, the number of bug reports and the number of patch reports are positively correlated with the OSS project success. These hypotheses focus on the role of OSS developers in the success of OSS projects. Unlike proprietary software development, OSS development relies on thousands of developers in the community to contribute to the project (Raymond, 2005; Thomas \& Hunt, 2004). We not only confirm the importance of non-core developers but we also identify several manifest factors that could indicate the developers' contributions - patch reports, bug reports, and forum activities. These findings are consistent with our analysis on the non-core developers' organizational structure. Non-core developers use forums to communicate with each other (Sharma et al., 2002). They contribute to the project mainly by submitting bug reports and patch reports (Tirole \& Lerner, 2002). Our research further confirms that these factors could show how active the non-core developers are.

More importantly, we confirm our hypotheses $\mathrm{H} 3 \mathrm{a}$ and $\mathrm{H} 3 \mathrm{~b}$ that the number of email lists and the number of CVS are positively related to OSS project success. These two results show the crucial role of core developers in OSS project success. In existing research, the role of core developers is under-explored. The core developers are not distinguished from the anonymous developers in the community. Our analysis demonstrates that core developers are one of the most important factors in an OSS project success. By examining the core developers' organizational structure, we also identify several indicators that could show how active the core developers are. CVS reports from core developers are the main channel for the core developers to collaborate and contribute to the project development (Crowston et al., 2004; Sharma et al., 2002). Therefore, it is consistent with our finding that these two variables are positively correlated with OSS project success. We also confirmed hypothesis $\mathrm{H} 4$ that the number of core developers is positively correlated with OSS project success. This further confirms the importance of core developers in the project success since a bigger number of core developers could mean that more development talents and contributions are available.

We also confirmed our hypotheses $\mathrm{H} 2 \mathrm{a}$ and $\mathrm{H} 2 \mathrm{~b}$ that the frequency of new software version release and the frequency of project news updates are both positively correlated with the OSS project success. This finding demonstrates the importance of promoting and publicizing OSS projects. In the OSS development community, thousands of projects are competing for developers' attention and contribution (Raymond, 2005; Thomas \& Hunt, 2004). For a project to succeed, its core developers need to actively promote and publicize their project in the community. This is a crucial way to signal the developers in the community that the project is active and developing fast.

Overall, our study demonstrates how interplay of information flows, enabling information technologies, and specific properties of organizational structure contribute to the success of the increasingly important OSS enterprise.

\section{Conclusion}

This study is the first stage of an investigation of sustainability of the OSS development model. It has several aspects we plan to improve in future research. For example, using the number of downloads as a dependent variable has certain limitations. Because open source could be downloaded freely, the actual deployment of downloads in projects is partly uncertain (Weiss, 2006). Several researchers have studied OSS project success. For instance, Fielding (1999) studies this by examining the successful project Tirole Apache. Our research is different from the studying successful cases since we also included the less successful projects in our data set. Hars and Or (2002) studied project sustainability by examining developers' incentives to participate in 
the project. Unlike our research, they did not distinguish the core developers from community developers. By studying differences in roles of core developers and community developers, we could potentially gain a better understanding of the organizational responsibilities of these two distinctive development groups.

Our research contribution could be summarized as follows. First, this research is one of the first to distinguish core developers from non-core developers in the community, and it is the first study of the distinctive roles of these two developer groups in OSS project success. Our dataset includes both successful projects and less successful projects. By studying both realms, we could potentially gain a more complete understanding of OSS development.

Second, open source developers could learn from our study how crucial is the role of promoting and publicizing the projects in the OSS community. They could adopt various strategies, such as releasing new versions of the project more often and paying more attention to motivating the developers in the community. And third, for industry practitioners, this research could be useful in predicting which projects have more potential to succeed as well as in deciding which projects should receive support.

In our future research, we plan to design a time series study by collecting data through the entire life spans of OSS projects. We will examine the factors that could help a small project reach a critical mass. We also plan to incorporate data from focus group interviews and surveys of OSS developers, with an accent on core developers.

\section{References}

Crowston, K., Annabi, H., Howison, J. \& Masango, C. (2004). Effective work practices for software engineering: Free/libre open source software development. WISER Workshop on Interdisciplinary Software Engineering Research, SIGSOFT 2004/FSE-12 Conference, Newport Beach, CA.

Crowston, K., Annabi, H., Howison, J. and Masango, C. (2005). Towards a portfolio of FLOSS project success measures. Proceedings of Workshop on Open Source Software Engineering, 26th International Conference on Software Engineering, Edinburgh. UK.

Fielding, R.Y. (1999). Shared leadership in the Apache project. Communications of the ACM, 42 (4), $42-$ 43.

Hann, I., Slaughter, S., Roberts, J., \& Fielding, R.Y. (2002). Economic incentives for participating in open source software projects. Proceedings of 23rd International Conference of Information Systems (ICIS), $365-372$.

Hars, A. \& Or, S. (2002). Working for free? Motivation for participating in open source projects. International Journal of Electronic Commerce, 6 (3), 25-39.

Krishnamurthy, S. (2002). Cave or community? An empirical examination of 100 mature open source projects. Working Paper, University of Washington, Bothell, Bothell, WA.

March, J.G. \& Simon, H.A. (1958). Organizations. New York: Wiley.

Markus, M.L., Manville, B. \& Agres, C.E. (2000). What makes a virtual organization work? Sloan Management Review, 42 (1), 13-26.

Miles, R.E. \& Snow, C.C. (1978). Organizational strategy, structure, and process. New York: McGrawHill.

Mintzberg, H. (1972). The structure of organizations. New Jersey: Prentice Hall.

Mockus, A., Fielding, R.T. \& Herbsleb, J. (2000). A case study of open source software development: the Apache server. Proceedings of the 22nd International Conference on Software Engineering, 263-279.

Moody, G. (2001). Rebel code: Linux and the open source revolution. Cambridge, MA: Perseus Press. 
Nohria, N. (1995). Note on organization structure. Harvard Business School Note, Reprint No. 9-491-083.

Raja, U. \& Tretter, M. (2006). Investigating open source project success: A data mining approach to model formulation, validation and testing, Working Paper, Texas A\&M University, College Station, Texas.

Raymond, E. (2005). The cathedral and the bazaar. Retrieved on December 12, 2005. from http://www.catb.org/ esr/writings/cathedral-bazaar/cathedral-bazaar/index.html

Robey, D. (1991). Designing organizations. Burr Ridge, IL: Irwin.

Schmidt, D.C. \& Porter, A. (2001). Leveraging open source communities to improve the quality and performance of open source software. In J. Feller, B. Fitzgerald, \& A. van der Hoek, (Eds.), Making Sense of the Bazaar: Proceedings of the 1st Workshop on Open Source Software Engineering.

Shaikh, M. \& Cornford, T. (2003). Version management tools: CVS to BK in the Linux kernel. Working Paper, retrieved December 1, 2005 from http://opensource.mit.edu/papers/shaikhcornford.pdf

Sharma, S., Sugumaran, V., \& Rajagopalan, B. (2002). A framework for creating hybrid open source software communities. Information Systems Journal, 12 (1), 7-26.

Stewart, K., Ammeter, A., \& Maruping, L. (2005). A preliminary analysis of the influences of licensing and organizational sponsorship on success in open source projects. Proceedings of the 38 Hawaii International Conference on System Sciences, 1-10.

Stewart, K. \& Gosain, S. (2006). The impact of ideology on effectiveness in open source software development teams. MIS Quarterly, 30 (2), 291-314.

Thomas, D. \& Hunt, A. (2004). Open source ecosystems. IEEE Software, 32 (1), 89-91.

Tirole, J. \& Lerner, J. (2002). Some simple economics of open source, Journal of Industrial Economics, 50 (2), 197-234.

Weiss, D. (2006). Measuring success of open source projects using web search engines, Working Paper, Poznan University of Technology, Poznán, Poland.

\section{Biography}

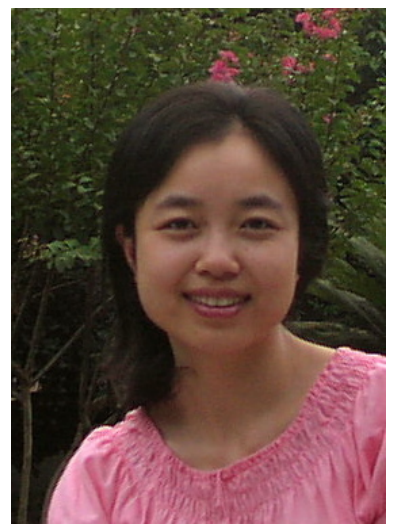

Dr. Ju Long is an assistant professor of Computer Information Systems at the McCoy School of Business at Texas State University-San Marcos. She has a Ph.D. degree from the University of Texas at Austin and a master degree from the University of Michigan in Ann Arbor. She studies technology's impact on business and how new software development methodologies are changing our world. 